\title{
Effect of microorganism on the degradation and formation of humic acid in Landfill Leachate
}

\author{
Juntao Cui 1,Jingyang Meng 1a,Wei Zhang 2b,Wei Wang 1c \\ 1JILIN Agriculture University Xincheng Street 2888 Changchun city Jilin Province China \\ 2 Changchun agricultural school Longjia JIUtai city Jilin Province China \\ a1186237339@qq.com,b1165728385@qq.com, \\ c1252675242@qq.com, *cuijuntao2005@163.com
}

\begin{abstract}
Keywords: landfill leachate, humic acid, microorganisms, degradation
Abstract.Humic acids are natural non-living organic substances and they are extremely resistant to biodegradation. Microorganisms are the driving force behind the transformation and mineralization of humic acids. However, their relative abundance and role during turnover of humic acids in landfill leachate treatments are still unclear, there is still a gap in our knowledge. This work was therefore undertaken with the aim of investigating the role of landfill leachate microbial communities in humic acids transformation and to highlight the problems, unsolved questions in leachate treatment. The quantities of humic acids and its ratio of E4/E6 in leachate were tested in the different cultivation condition. The results shown: Compared with the blank, the formation and transformation of HA in different species are not the same, and 2,3,4 strain has a role in the degradation of HA respectively., while number 1,5 strain has promoted the formation of HA. Five leachate dominant species: Bacillus sp.1; Bacillus sp.2; Bacillus sp.3; Pseudomonas sp.4; Pseudomonas sp.5(1) In the condition of carbon source, the microorganism can synthesize the carbon source to synthesize the humus, and when the carbon source is lack, it can degrade the humus, which can be used as the nutrient substance.(2) Under the different dilution degrees,microorganisms have different ability to degrade humus.(3) The microorganisms in the leachate have the ability to degrade humic substances, can be changed the environment in the leachate, so as to achieve the purpose of reducing the humus in the leachate, and ultimately to reach the standard.
\end{abstract}

\section{Introduction}

landfill is the most common waste disposal method, and there are many pollution problems, especially in the process of landfill leachate. Landfill leachate is a kind of high concentration organic wastewater due to municipal solid waste (MSW) was stacked in the landfill site generated by the microbial decomposition, rainwater leaching and long-term immersion of surface water and groundwater, if not be directly discharged into the environment will cause serious pollution. The water quality characteristics of landfill leachate are mainly characterized by high concentration of organic substance, high quality of ammonia nitrogen, high fluctuation of water quality and so on. studies have indicated that humus (HS) is recognized as the main component of the organic carbon in landfill leachate and the difficult degradation part. It is also the main substance that causes the chroma of the landfill leachate. It is generally referred to as "difficult to control", and the content of TOC is $60 \%$. With the time extension, the higher the content of humic substances, especially the rich in acid. Acid Humic (HA) (humic acid) as a natural colloid with a large number of functional groups and adsorption sites. The humus in the landfill leachate is the cause of the color, the smell, the corrosion of the water pipe and the sediment. Therefore, the research of humus in the landfill leachate treatment and environmental protection.Although the humus research has been 200 years of history, and it has obtained a lot of knowledge is concerned, there is still some confusion or stultify and need to be further studied. 


\section{Experimental Design}

\section{Experimental materials}

Garbage leachate from Changchun municipal solid waste treatment center, was built in April 2009, in October 2010, put in to use.The design of the use of 10 years, the design of garbage daily processing capacity of 2600 tons, treatment of sanitary landfill for domestic refuse.

The strains were isolated from the leachate, belonging to the genus Bacillus and Pseudomonas. Namely:Bacillus sp.1; Bacillus sp.2; Bacillus sp.3; Pseudomonas sp.4; Pseudomonas sp.5

\section{Experimental design}

Experiment 1: Effect of different carbon sources on the transformation of humic acid

Dilute the landfill leachate by twenty percent $(20 \mathrm{ml}$ leachate with $80 \mathrm{ml}$ ultra pure water), make 5 samples, add respectively $2 \mathrm{~g}$ sucrose, $2 \mathrm{~g}$ starch, $2 \mathrm{~g}$ glucose, $2 \mathrm{~g}$ Cellulose sodium and a blank sample. Put into the oscillator, shaking for 7 days under $28^{\circ} \mathrm{C}$ and 145 RPM.To carry out the separation and purification of the bacteria after 7 days.After the purification of the bacteria was kept in the test tube.At this time, the 5 samples were added to the $20 \mathrm{ml}$ leachate. Continue to culture for 7 days (a total of 14 days), and continue to separate and purify, testing whether the former kinds of strains still exist. Extracting humic substances from the leachate, then measuring the absorbance and determinating carbon content of humic acid.

Experiment 2: Effect of different inoculation amount on the transformation of humic acid

All of the strains in the experiment 1 are added to the aquae sterilisata are made of Bacteria liquid(Purpose is to add an excess of indigenous bacteria in the leachate), After 3 days of incubation in the oscillator, the bacteria solution at $20 \mathrm{ml}, 40 \mathrm{ml}, 50 \mathrm{ml}, 60 \mathrm{ml}$ and $80 \mathrm{ml}$ volume added to $300 \mathrm{ml}$ Erlenmeyer flask, then correspond to adding $80 \mathrm{ml}$ and $60 \mathrm{ml}, 50 \mathrm{ml}, 40 \mathrm{ml}, 20 \mathrm{ml}$ of leachate, so that each triangular bottle containing $100 \mathrm{ml}$ of liquids, to ensure that the dissolved oxygen content as much as possible the same. After 3 days of incubation in the oscillator, then extract the humus and measuring a light absorption value and determinating carbon content of humic acid.

Experiment 3: Effect of different strains on the transformation of humic acid in the leachate

The samples of the experimental 2 were purified. Finally, 5 strains were selected(Bacillus sp.1; Bacillus sp.2; Bacillus sp.3; Pseudomonas sp.4; Pseudomonas sp.5).

Make a single bacterial solution after screening the bacteria, each $50 \mathrm{ml}$, respectively added $100 \mathrm{ml}$ leachate. Culture for 3 days, then extract the humus and measured absorbance and carbon of humic acid.

\section{Experimental method:}

Determination method of humic acid:Difference subtraction HE and water soluble carbon were extracted by $\mathrm{NaOH}$ and $\mathrm{Na} 4 \mathrm{P} 2 \mathrm{O} 7 \cdot 10 \mathrm{H} 2 \mathrm{O} ; \mathrm{FA}$ and water soluble carbon were filtered under acidic conditions;HA was obtained by difference subtraction.E4/E6:Ratio of $465 \mathrm{~nm}$ and $665 \mathrm{~nm}$ absorbance at wavelength.

The higher the E4/E6 ratio, the more simple the molecular weight of them, the smaller the molecular weight, the lower the oxidation degree, the content of carboxyl, phenol group and so on.

\section{Experimental Data and Analysis}

Experiment 1 : Effect of different carbon sources on the transformation of humic acid

Compared with "Leachate", Carbon content of HA increased significantly with the addition of carbon source,while the blank sample has a small reduction.Preliminary analysis, the humic acid was synthesized by the addition of carbon source under the action of microorganisms. The decrease of carbon content of HA in the blank sample without adding carbon source may be due to humus fractions are consumed by microbial metabolism In the presence of dissolved oxygen, So as to transform it into the nutritional substances.The E4/E6 of all samples was much larger than that of leachate.Under the effect of external carbon source and dissolved oxygen, the molecular structure of humic acid is simple, and the oxidation degree is low(Table 1).

In the condition of carbon source, the microorganism can synthesize the carbon source to synthesize the humus, and when the carbon source is lack, it can degrade the humus, which can be 
used as the nutrient substance. The following will continue to be validated by the experiment. Experiment 2 Effect of different inoculation amount on the transformation of humic acid

Samples inoculated with microorganisms, the total carbon content of HA was lower than that of "100\%leachate". The culture environment has not satisfied the living of the microorganism. The carbon source of the microorganism depends on the decomposition of humus to meet its growth, while the microorganism has different degradation ability under different concentration of leachate(Table 2).

Table 1. Effect of different carbon sources on the transformation of humic acid

\begin{tabular}{lllllll}
\hline Absorbance & Starch & Sucrose & Glucose & Cellulose & Blank $^{\mathrm{a}}$ & Leachate $^{\mathrm{b}}$ \\
\hline $400 \mathrm{~nm}$ & 0.05 & 0.033 & 0.053 & 0.033 & 0.028 & 0.032 \\
$465 \mathrm{~nm}$ & 0.028 & 0.015 & 0.085 & 0.015 & 0.014 & 0.017 \\
$600 \mathrm{~nm}$ & 0.006 & 0.004 & 0.024 & 0.005 & 0.004 & 0.008 \\
$665 \mathrm{~nm}$ & 0.004 & 0.002 & 0.020 & 0.003 & 0.002 & 0.006 \\
E4/E6 & 7 & 7.5 & 4.25 & 5 & 7 & 2.83 \\
Toc $(\mathrm{mg} / \mathrm{l})$ & 88.91 & 67.74 & 114.31 & 86.79 & 24.29 & 25.40 \\
\hline
\end{tabular}

Note: aSample footnote A.Without adding any additional carbon source.

bSample footnote B.As the sample of the leachate volume ratio is $(20+20) /(20+80+20)$

$=1 / 3$, so there will be no shock culture of leachate diluted $1 / 3$ made of samples"Leachate".

Table 2. Effect of different inoculation amount on the transformation of humic aci

\begin{tabular}{lllllll}
\hline Absorbance & 1/5leachate & 2/5leachate & 1/2leachate & 3/5leachate & 4/5leachate & leachate \\
\hline $400 \mathrm{~nm}$ & 0.022 & 0.049 & 0.047 & 0.08 & 0.154 & 0.07 \\
$465 \mathrm{~nm}$ & 0.012 & 0.025 & 0.026 & 0.05 & 0.089 & 0.039 \\
$600 \mathrm{~nm}$ & 0.004 & 0.011 & 0.011 & 0.024 & 0.041 & 0.008 \\
$665 \mathrm{~nm}$ & 0.003 & 0.007 & 0.008 & 0.017 & 0.03 & 0.004 \\
E4/E6 & 4 & 3.57 & 3.25 & 2.941 & 2.967 & 9.75 \\
Toc (mg/1) & 16.91 & 17.57 & 23.43 & 21.39 & 24.08 & 125.12 \\
Degradation & $32.42 \%$ & $64.89 \%$ & $62.55 \%$ & $71.55 \%$ & $75.94 \%$ & $/$ \\
\hline
\end{tabular}

Experiment 3 Effect of different strains on the transformation of humic acid in the leachate

Compared with the blank, the formation and transformation of HA in different species are not the same, and 2,3,4 strain has a role in the degradation of HA, while number 1,5 strain has promoted the formation of HA(Table 3). Overall, these 5 species of bacteria in the process of transformation of humus mainly played a role in degradation, individual species also play a role in the formation of humus fractions. This argument is hardly mentioned in the literature, as a living organism, as a living entity, has the common character of living. Under the condition of comfort and ease, it can choose to be used more directly, the synthesis of microorganisms has been proved by a lot of arguments. In the lack of nutrients, microorganisms also split into humus composition, degradation of the organic carbon source can be absorbed by itself.

Table 3. Effect of different strains on the transformation of humic acid in the leachate

\begin{tabular}{lllllll}
\hline Absorbance & 1 & 2 & 3 & 4 & 5 & Blank \\
\hline $400 \mathrm{~nm}$ & 0.070 & 0.204 & 0.116 & 0.047 & 0.068 & 0.069 \\
$465 \mathrm{~nm}$ & 0.028 & 0.111 & 0.061 & 0.021 & 0.028 & 0.028 \\
$600 \mathrm{~nm}$ & 0.008 & 0.043 & 0.025 & 0.006 & 0.006 & 0.005 \\
$665 \mathrm{~nm}$ & 0.004 & 0.030 & 0.020 & 0.004 & 0.004 & 0.001 \\
E4/E6 & 7 & 3.7 & 3.05 & 5.25 & 7 & 28 \\
Toc (mg/l) & 116.73 & 45.86 & 77.12 & 54.19 & 167.80 & 104.22 \\
\hline
\end{tabular}

Note: Table notes. The strains were isolated from the leachate, belonging to the genus Bacillus and Pseudomonas. Namely:Bacillus sp.1; Bacillus sp.2; Bacillus sp.3; Pseudomonas sp.4; Pseudomonas sp.5

In different dilution degree, some of the nutrients in the leachate are also reduced the concentration, in a suitable condition, better to be absorbed by the microorganism. In the original high concentration of organic wastewater, microbial survival may be inhibited, so the study of 
dilution is very effective in treatment of leachate.

The microorganisms in the leachate have the ability to degrade humic substances, can be changed the environment in the leachate, so as to achieve the purpose of reducing the humus in the leachate, and ultimately to reach the standard.The large quantities of adding foreign bacteria is useless, if it can change the environment and reduce the processing cost, it is an effective way to deal with the actual production.From the current view, the humus is broadly defined as the organic matter which is formed by the microbial decomposition of dead organisms ". However, this definition is applicable to the water and leachate in the humus to be explored.

We found that people don't want to use a more intense chemical reagent to separate the components of humus, and want to use a more moderate approach to get deeper. And some scholars have the same doubt, now we are separated from the rich in acid and humic acid is the nature of the existence of the material. But one point is certain, the composition and structure of humus is really affected by the role of microorganisms, and will have been affected.Landfill leachate is different from the general water body, and the humus is mainly influenced by the microbial metabolic activity in the landfill. However, in the leachate, the microbial activity is not active. Humus is the main component of landfill leachate organic carbon and difficult to degrade, and it is also the main material, which is the main material of landfill leachate. It is generally referred to as "difficult to control", which can account for about $60 \%$ of TOC. While the landfill leachate this special environment, it seems that is not conducive to microbial decomposition and transformation of humus.In the United States, many authoritative experts agree that humic acid is a complex mixture, in recent years, there is no new discovery in this area. In the study of humus, the need to be on the basis of the existing theory, a bold attempt to innovate, not limited to one or several similar methods applied to different processing environment.

\section{Conclusions}

(1)In the condition with rich carbon source, the microorganism can synthesize the carbon source to synthesize the humus, and when the carbon source is lack, it can degrade the humus, which can be used as the nutrient substance.

(2)Under the different dilution degrees,microorganisms have different ability to degrade humus.

\section{Acknowledgments:}

This work was financially supported by National Basic Research Program of China(2009CB426308).National applying Research Program of China(2012GB2 B100112) major scientific and technological research Program of Jilin provincial science and technology department(20130204041NY;20160204006YY).

\section{References}

[1]Xiong Tiangong . Soil organic matter chemistry . Beijing: Science Press, (1988).

[2]Do Sen, Zhang Jihong, Yan Li. Agricultural sustainable development: Northeastern University press, (1995).

[3]Qian Guoping, Qian Jin. The composition and properties of Soil Humus in the soil of Anhui province, (1993)

[4]Qian Xuede, Guo Zhiping. Advances in the technology of water conservancy and hydropower in the composite liner system of landfill., Vol.17:64-68 (1997)

[5]Yang Yujiang, Zhao Youcai. Journal of environmental sciences, Vol 27(1): 92 -95 (2007).

[6]Ding Rui. Journal of Qinghai University: Natural Science edition, Vol 24 (2) :20- 22(2006).

[7]Sun Youning, Feng Zhaohui, Yu Meiling.]humic acid. Vol 1 : 12- 15(2005).

[8]Dou Sen, Liu Wei, Zhang Jinjing. The influence of soil organic fertilizer on the optical properties of the rich. Changchun: Jilin Agricultural University(1981). 
[9]Wang Luochun, et al. Environmental pollution and control, Vol 11(2): 88- 90(1998).

[10]Hu Yunliang. Shanghai environmental science, Vol 18(1): 37-44(1999).

[11]Gu Xiasheng, Huang Mingrong, Wang Zhansheng, et al. Water treatment engineering. Tsinghua University press,(1985).

[12]Chen Jiajun, Zhang Jun, Wang Hong. China Environmental science,Vol19(3):234-237. (1999).

[13]Zhang Yuzhen. Groundwater and soil water dynamics. Wuhan: China Water Conservancy and Hydropower press,(1996).

[14]Yang Zhifeng, Wang Jinsheng, Wang Li,Journal of hydraulic engineering, Vol 9:16-21. (2001). [15]Stevenson F J. Humus chemistry: genesis, composition and reactions . New York: John Wiley \& Sons Inc, 1982. 